\title{
The deadly line linking sympathetic overdrive, dipping status and vascular risk: critical appraisal and therapeutic implications
}

\author{
Francesca Santilli, Paola Simeone, Damiano D’Ardes and Giovanni Davì
}

Hypertension Research (2016) 39, 404-406; doi:10.1038/hr.2016.27; published online 17 March 2016

$\mathrm{H}$ ypertension is a major risk factor for cardiovascular disease and death. The chronic elevation of blood pressure (BP) is a silent disorder because its progression is largely asymptomatic. However, the impact of this disorder is deafening, and hypertension is a cause of cardiovascular disease, end-organ damage and death. Hypertension is defined as systolic BP $\geqslant 140 \mathrm{~mm} \mathrm{Hg}$ and/or diastolic $\mathrm{BP} \geqslant 90 \mathrm{~mm} \mathrm{Hg}$ based on evidence from randomized controlled trials showing that patients with these BP values can benefit from treatment-induced BP reductions. ${ }^{1}$

Office measurements of BP are frequently inaccurate. Ambulatory BP monitoring offers a more accurate diagnosis, more detailed readings of average BPs, better BP measurement during sleep, fewer false positives by detecting more white-coat hypertension and fewer false negatives by detecting more masked hypertension. ${ }^{2}$

The physiological circadian rhythm of BP comprises a nocturnal decrease; the 'dipping status' represents the behavior of BP on transitioning from wakefulness to sleep depending on whether BP falls, rises or remains constant and is mainly quantified through the so-called 'night per day BP ratio.' Using this index, patients can be arbitrarily classified into four groups: extreme dippers (ratio $\leqslant 0.8)$, dippers $(0.8<$ ratio $\leqslant 0.9)$, nondippers or mild dippers $(0.9<$ ratio $\leqslant 1.0)$, and reverse dippers or risers (ratio $\geqslant 1.0$,

F Santilli, P Simeone, D D'Ardes and G Davì are at Center of Excellence on Aging, 'G. d'Annunzio' University Foundation and Department of Medicine and Aging, University of Chieti 'G. d'Annunzio' School of Medicine, Chieti, Italy

E-mail: f.santilli@unich.it indicating a nocturnal increase in BP compared with daytime mean values). ${ }^{3}$

The reverse-dipper BP pattern is an independent risk factor for $\mathrm{CV}$ events and stroke, ${ }^{4}$ lacunar infarction ${ }^{5}$ and chronic kidney disease. ${ }^{6,7}$ In the Norwegian Stroke in the Young Study, the non-dipping BP pattern was common and was associated with increased aortic stiffness, ${ }^{8}$ a marker of subclinical organ damage in treated and untreated dipper hypertensive patients. ${ }^{9}$

In this study, Di Raimondo et al. ${ }^{3}$ reported an inter-individual variability in sympathovagal balance among hypertensive individuals, with a higher degree of sympathetic activation being detected in reverse dippers. These authors were also able to confirm in their cohort the observation that non-dipping is related to more advanced disease (end-organ damage, particularly reduced renal function and left ventricular hypertrophy).

The questions arising from and possible practical implications of their findings are manifold: first, whether the higher autonomic activation vs other features of the non-dipper or reverse-dipper status reflects and carries a higher vascular burden; and second, whether the therapeutic management of patients should be tailored in terms of medication choice and circadian drug regimen for the different night per day BP patterns.

Whether the poorer cardiovascular prognosis that is associated with the nondipper status is a function of the enhanced activation of the sympathetic nervous system (SNS) is a challenging question because of the complexity and multiplicity of the mechanisms that have been implicated in the blunted nighttime BP decline and to the heterogeneity of methods employed for SNS activation assessment.

Non-dipper hypertensive patients show a significantly higher extent of platelet turnover and activation, as reflected by the enhanced mean platelet volume and soluble CD40L levels compared with those of dippers and normotensive individuals. ${ }^{10}$ Interestingly, recent observations would suggest a major role of sympathetic stimulation as a determinant of atherothrombosis, being able to facilitate thrombopoiesis by promoting megakaryocyte adhesion, migration and proplatelet formation. ${ }^{11}$

However, in addition to increased sympathetic activity, blunted nighttime BP decline has also been associated with a number of pathophysiological elements, such as primary hyperaldosteronism, obstructive sleep apnea syndrome, ${ }^{12}$ salt sensitivity, increased sodium intake and reduced insulin sensitivity; although it is conceivable that their effects as contributors may be deeply intertwined and linked to the autonomic activation. For instance, the G972R polymorphism of the IRS-1 gene is associated with insulin resistance, salt sensitivity and non-dipper hypertension. ${ }^{13-15}$ Low-plasma brain-derived neurotrophic factor is associated with patients showing a reverse-dipper pattern of nocturnal $\mathrm{BP}$, in which an imbalance of cardiac autonomic function may be partly involved. ${ }^{16}$ Moreover, the dysfunction of the autonomic nervous system may mediate the influences of stress, sleep disorders, deterioration of the endocrine system and oxidative stress. In this regard, extensive evidence shows that oxidative stress has a central role in the pathophysiology of essential hypertension, ${ }^{17}$ partly through an 
interaction with SNS activation. ${ }^{18}$ It is becoming increasingly clear that the reactive oxygen species that are produced in the central nervous system promote sympathetic outflow, inflammation and hypertension ${ }^{19}$ (Figure 1).

The difficulty in quantifying the contribution of sympathetic overactivation in dipping status and related vascular outcomes becomes even more complicated when considering the reliability and heterogeneity of the tools that are used to assess SNS activation. Several studies in recent years have attempted to detect the presence of sympathetic activation in hypertensive patients by making use of two quite rough indices of adrenergic drive: plasma noradrenaline levels and heart rate (HR). ${ }^{20}$ An analysis of plasma noradrenaline demonstrated that in patients with essential hypertension, the plasma levels of the adrenergic neurotransmitter are 25-30\% greater than those in age-matched normotensive control subjects. ${ }^{20}$ The pathophysiological significance of an increase in plasma noradrenaline in hypertension is uncertain because an increase in plasma noradrenaline does not only necessarily reflect an enhanced sympathetic drive but may also depend on a reduced reuptake of the neurotransmitter from peripheral nerve endings and/or on a decrease in its tissue clearance. ${ }^{20,21}$

The measurement of HR variability currently represents the most used noninvasive form of assessment of autonomic nervous system activity. ${ }^{3,22}$ A reduced HR variability usually indicates an alteration of the sympatho-vagal balance in favor of the SNS: this alteration could be an effect of an increased sympathetic tone, decreased parasympathetic tone or both. ${ }^{3}$ Moreover, $\mathrm{HR}$ is not a specific marker of cardiac adrenergic activity because it is also regulated by vagal cholinergic influences: for this reason, changes in HR cannot be taken as a measure of adrenergic drive without the benefit of the response to the $\beta$-adrenergic blockade to assess the sympathetic contribution. ${ }^{23}$

Despite the pathophysiological and epidemiological relevance of non-dippers and reverse dippers in terms of poor prognosis and the theoretical rationale for a tailored therapeutic strategy fitting the patient's circadian pattern with the drug's pharmacodynamics, night and night per day $\mathrm{BP}$ ratio responses to the most commonly prescribed antihypertensive agents have been poorly assessed.

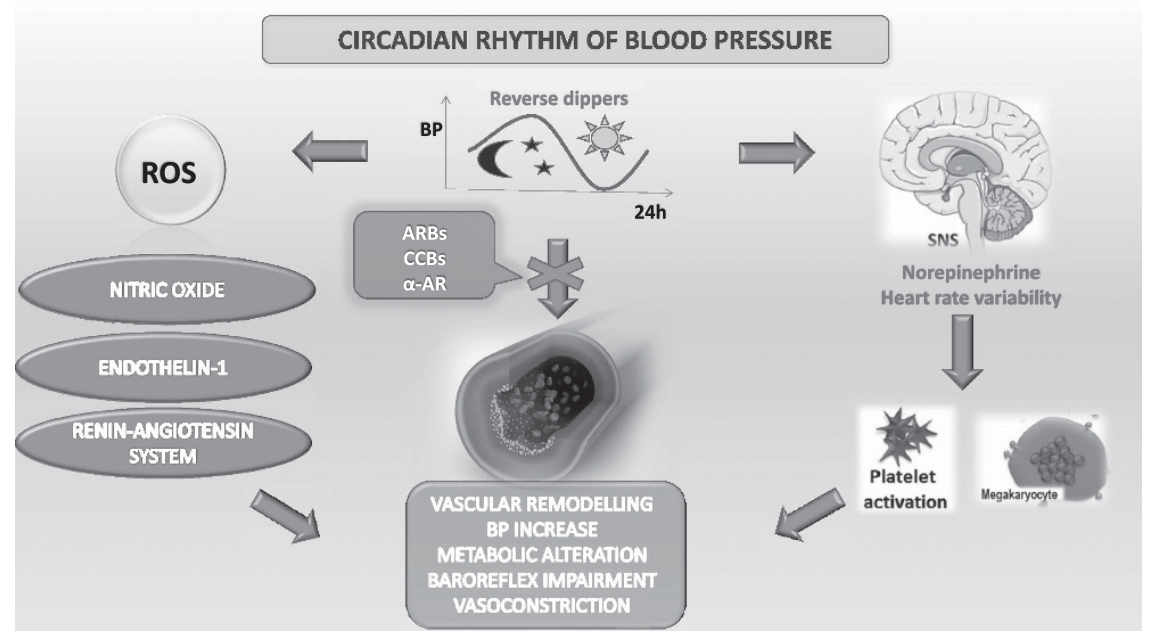

Figure 1 The abnormal autonomic modulation of BP may be a connection between the circadian fluctuations of the autonomic nervous system's activity and the BP values in hypertensive subjects. SNS is critically influenced at the central and peripheral levels by the most relevant factors regulating vascular function, such as NO, ROS, ET and the renin-angiotensin system. Sympathetic activity may induce sustained increase in BP through several mechanisms by causing peripheral vasoconstriction, potentiating cardiac contraction, reducing venous capacitance, affecting renal sodium and through water excretion; through baroreflex dysfunction, SNS facilitates thrombopoiesis by promoting megakaryocyte adhesion, migration and proplatelet generation. Several drugs, such as ARBs, CCB and AR, can normalize the circadian BP pattern to a dipper profile. Chronotherapy may optimize the treatment of hypertension based on an individual circadian BP profile and may reduce $\mathrm{CV}$ risk. AR, $\alpha$-adrenergic antagonists; ARBs, angiotensin II type 1 receptor blockers; BP, blood pressure; CCB, calcium channel blocker; CV, cardiovascular; ET, endothelin; NO, nitric oxide; ROS, reactive oxygen species; SNS, sympathetic nervous system. A full color version of this figure is available at the Hypertension Research journal online.
The angiotensin II type 1 receptor blocker olmesartan may restore nighttime BP decline, as seen with diuretics and sodium restriction, possibly by enhancing daytime sodium excretion. Olmesartan may also relieve cardiorenal load through the normalization of circadian BP rhythm, in addition to having the powerful ability to block the renin-angiotensin system. ${ }^{24}$ Another study has shown that telmisartan, but not ramipril, can normalize the circadian BP pattern to a dipper profile in a larger proportion of hypertensive patients. ${ }^{25}$ Among $\alpha$-adrenergic blockers, doxazosin markedly affects the nocturnal BP dipping status of hypertensive subjects, with an apparently greater reduction of nighttime and daytime $\mathrm{BP}$ in reverse dippers. Doxazosin had no significant effect on nighttime BP in extreme dippers, suggesting that $\alpha$-adrenergic tone decreases, at least during the nighttime, in extreme dippers. ${ }^{26}$

Ambulatory BP monitoring, in approximately 500 black and white essential hypertensive patients, revealed that atenolol therapy, when administered upon rising for 18 weeks, induced no change in night per day $\mathrm{BP}$ ratios in whites and a significant increase in night per day BP ratios in blacks, a population that displays increased nighttime BP levels and a higher incidence of stroke, congestive heart failure, and renal disease. ${ }^{27}$ Such a null or paradoxical response to a $\beta$ blocker agent, which is expected to blunt SNS activation through its negative lusitropic effect, is explained by the short duration of treatment or by the unfavorable time of medication administration.

Indeed, regardless of the medication that is used, chronotherapy may be a potential cost-effective means of both tailoring and optimizing the treatment of hypertension based on an individual circadian BP profile and an effective option to reduce $\mathrm{CV}$ risk. ${ }^{28}$

In hypertensive patients with chronic renal failure, the calcium channel blocker isradipine exhibits a greater BP-lowering effect on nighttime BP when administered at 2000 hours compared with an 0800 hours administration and, under these conditions, effectively restores the circadian BP rhythm. Similarly, the administration of an $\alpha$-adrenergic antagonist to patients with primary hypertension exhibits more pronounced effects on BP control when administered before sleeping. ${ }^{29}$ A once-daily evening, rather than morning, ingestion schedule of the angiotensin II type 1 receptor blockers irbesartan, olmesartan, telmisartan and valsartan exerts a greater therapeutic effect on sleeping BP and a significant increase in the sleep-time relative BP decline, 
with a normalization of the circadian BP profile toward a greater dipping pattern independent of drug terminal half life. ${ }^{28}$

In addition to the timing of medication administration, potential areas for therapeutic interventions may include lifestyle modifications, such as habitual physical exercise and improvement in sleep quality, which reduce both SNS activation and CV risk.

Further studies are needed to examine the influence of 'dipping status' and circadian clock on the molecular mechanisms that are involved in hypertension, which may ultimately provide breakthroughs in our understanding and treatment of this silent killer.

\section{CONFLICT OF INTEREST}

The authors declare no conflict of interest.

1 Mancia G, Fagard R, Narkiewicz K, Redon J, Zanchett A, Böhm M, Christiaens T, Cifkova R, De Backer G Dominiczak A, Galderisi M, Grobbee DE, Jaarsma $T$, Kirchhof P, Kjeldsen SE, Laurent S, Manolis AJ, Nilsson PM, Ruilope LM, Schmieder RE, Sirnes PA, Sleight P, Viigimaa M, Waeber B, Zannad F, Redon J, Dominiczak A, Narkiewicz K, Nilsson PM, Burnier M, Viigimaa M, Ambrosioni $E$, Caufield $M$, Coca A, Olsen $\mathrm{MH}$, Schmieder RE, Tsioufis C, van de Borne $\mathrm{P}$, Zamorano JL, Achenbach S, Baumgartner H, Bax JJ, Bueno H, Dean V, Deaton C, Erol C, Fagard R, Ferrari R, Hasdai D, Hoes AW, Kirchhof P, Knuuti J, Kolh P, Lancellotti P, Linhart A, Nihoyannopoulos P, Piepoli MF, Ponikowski P, Sirnes PA, Tamargo JL, Tendera M, Torbicki A, Wijns W, Windecker S, Clement DL, Coca A, Gillebert TC, Tendera M, Rosei EA, Ambrosioni E, Anker SD, Bauersachs J, Hitij JB, Caulfield M, De Buyzere M, De Geest S, Derumeaux GA, Erdine S, Farsang C, Funck-Brentano C, Gerc V, Germano G, Gielen S, Haller H, Hoes AW, Jordan J, Kahan T, Komajda M, Lovic D, Mahrholdt H, Olsen MH, Ostergren J, Parati G, Perk J, Polonia J, Popescu BA, Reiner Z, Rydén L, Sirenko Y, Stanton A, Struijker-Boudier H, Tsioufis C, van de Borne P, Vlachopoulos C, Volpe M, Wood DA. The Task Force for the management of arterial hypertension of the European Society of Hypertension (ESH) and of the European Society of Cardiology (ESC). European Heart Journal 2013; 34: 2159-19.

2 Solak Y, Kario K, Covic A, Bertelsen N, Afsar B, Ozkok A, Wiecek A, Kanbay M. Clinical value of ambulatory blood pressure: is it time to recommend for all patients with hypertension? Clin Exp Nephrol 2015; 20: 14-22.

3 Di Raimondo D, Miceli G, Casuccio A, Tuttolomondo A, Buttà C, Zappulla V, Schimmenti C, Musiari G, Pinto A. Does sympathetic overactivation feature all hypertensives? Differences of sympathovagal balance according to night/day blood pressure ratio in patients with essential hypertension. Hypertens Res 2016; 39 : 440-448.

4 Ohkubo T, Hozawa A, Yamaguchi J, Kikuya M, Ohmori K, Michimata M, Matsubara M, Hashimoto J, Hoshi H, Araki T, Tsuji I, Satoh H, Hisamichi S, Imai Y. Prognostic significance of the nocturnal decline in blood pressure in individuals with and without high 24-h blood pressure: the Ohasama study. J Hypertens 2002; 20: 2183-2189.

5 Yan B, Peng L, Dong Q, Zheng F, Yang P, Sun L, Gong S, Zeng L, Wang G. Reverse-dipper pattern of blood pressure may predict lacunar infarction in patients with essential hypertension. Eur J Neurol 2015; 22: 1022-1025.

6 Hermida RC, Ayala DE, Smolensky MH, Mojón A, Fernández JR, Crespo JJ, Moyá A, Ríos MT, Portaluppi F. Chronotherapy improves blood pressure control and reduces vascular risk in CKD. Nat Rev Nephrol 2013; 9: 358-368.

7 O'Flynn AM, Madden JM, Russell AJ, Curtin RJ, Kearney PM. Isolated nocturnal hypertension and subclinical target organ damage: a systematic review of the literature. Hypertens Res 2015; 38: 570-575.

8 Saeed S, Waje-Andreassen U, Tone Lønnebakken MT, Fromm A, Øygarden H, Naess H, Gerdts E. Covariates of non-dipping and elevated night-time blood pressure in ischemic stroke patients: the Norwegian Stroke in the Young Study. Blood Press 2015; 23: 1-7.

9 Natale F, Aronne L, Russo MG, Calabrò R. Ambulatory arterial stiffness index: a marker of subclinical organ damage in treated and untreated dipper hypertensive patients. Hypertens Res 2011; 34: 161.

10 Surgit $\mathrm{O}$, Erturk M, Akgul O, Pusuroglu H, Korkmaz AF, Isiksacan N, Gul M, Uzun F, Ozal E, Eksik A. Assessment of mean platelet volume and soluble CD40 ligand levels in patients with non-dipper hypertension, dippers and normotensives. Clin Exp Hypertens 2015; 37: 70-74.

11 Chen S, Du C, Shen M, Zhao G, Xu Y, Yang K, Wang $X$, Li F, Zeng D, Chen F, Wang S, Chen M, Wang C, He T, Wang F, Wang A, Cheng T, Su Y, Zhao J, Wang J. Sympathetic stimulation facilitates thrombopoiesis by promoting megakaryocyte adhesion, migration and proplatelet formation. Blood 2016; 127 : 1024-1035.

12 Parati G, Ochoa JE, Bilo G, Mattaliano P, Salvi P, Kario K, Lombardi C. Obstructive sleep apnea syndrome as a cause of resistant hypertension. Hypertens Res 2014; 37: 601-613.

13 Dziwura J, Bińczak-Kuleta A, Miazoowski T, Ziemak J, Widecka K. The associations between G972R polymorphism of the IRS-1 gene, insulin resistance, salt sensitivity and non-dipper hypertension. Hypertens Res 2011; 34: 1082-1086.

14 Leu HB, Chung CM, Lin SJ, Chiang KM, Yang HC, Ho HY, Ting CT, Lin TH, Sheu SH, Tsai WC, Chen JH, Yin WH, Chiu TY, Chen Cl, Fann CS, Chen YT, Pan WH, Chen JW. Association of circadian genes with diurnal blood pressure changes and non-dipper essential hypertension: a genetic association with youngonset hypertension. Hypertens Res 2015; 38 : 155-162.

15 Oh SW, Han SY, Han KH, Cha RH, Kim S, Yoon SA, Rhu DR, Oh J, Lee EY, Kim DK, Kim YS. Morning hypertension and night non-dipping in patients with diabetes and chronic kidney disease. Hypertens Res 2015; 38: 889-894.

16 Kadoya M, Koyama $H$, Kanzaki A, Kurajoh M, Hatayama M, Shiraishi J, Okazaki H, Shoji T, Moriwaki Y, Yamamoto T, Inaba M, Namba M. Plasma brain-derived neurotrophic factor and reverse dipping pattern of nocturnal blood pressure in patients with cardiovascular risk factors. PLOS ONE 2014; 9: e105977.

17 González J, Valls N, Brito R, Rodrigo R. Essential hypertension and oxidative stress: new insights. World J Cardiol 2014; 6: 353-366.

18 Santilli F, D'Ardes D, Davì G. Oxidative stress in chronic vascular disease: from prediction to prevention. Vascul Pharmacol 2015; 74: 23-37.

19 Montezano AC, Touyz RM. Reactive oxygen species, vascular Noxs, and hypertension: focus on translational and clinical research. Antioxid Redox Signal 2014; 20 : 164-182.

20 Grassi G, Seravalle G, Quarti-Trevano F. The 'neuroadrenergic hypothesis' in hypertension: current evidence. Exp Physiol 2010; 95: 581-586.

21 Grassi G, Bombelli M, Buzzi S, Volpe M, Brambilla G. Neuroadrenergic disarray in pseudo-resistant and resistant hypertension. Hypertens Res 2014; 37: 479-483.

22 Yamaguchi Y, Wada M, Sato H, Nagasawa H, Koyama S, Takahashi Y, Kawanami T, Kato T. Impact of nocturnal heart rate variability on cerebral small-vessel disease progression: a longitudinal study in communitydwelling elderly Japanese. Hypertens Res 2015; 38: 564-569.

23 Grassi G, Mark A, Esler M. The sympathetic nervous system alterations in human hypertension. Circ Res 2015; 116: 976-990.

24 Fukuda M, Yamanaka T, Mizuno M, Motokawa M, Shirasawa Y, Miyagi S, Nishio T, Yoshida A, Kimura G. Angiotensin II type 1 receptor blocker, olmesartan, restores nocturnal blood pressure decline by enhancing daytime natriuresis. J Hypertens 2008; 26: 583-588.

25 Gosse P, Schumacher H. Effect of telmisartan vs ramipril on 'dipping' status and blood pressure variability: pooled analysis of the PRISMA studies. Hypertens Res 2014; 37: 151-157.

26 Kario K, Schwartz JE, Pickering TG. Changes of nocturnal blood pressure dipping status in hypertensives by nighttime dosing of alpha-adrenergic blocker, doxazosin: results from the HALT study. Hypertension 2000; 35: 787-794.

27 Chapman AB, Cotsonis G, Parekh V, Schwartz GL, Gong Y, Bailey KR, Turner ST, Gums JG, Beitelshees AL, Cooper-DeHoff R, Boerwinkle E, Johnson JA. Night blood pressure responses to atenolol and hydrochlorothiazide in black and white patients with essential hypertension. Am J Hypertens 2014; 27 : 546-554.

28 Hermida RC, Ayala DE, Fernández JR, Portaluppi F, Fabbian F, Smolensky MH. Circadian rhythms in blood pressure regulation and optimization of hypertension treatment with ACE inhibitor and ARB medications. Am J Hypertens 2011; 24: 383-391.

29 Rudic RD, Fulton DJ. Pressed for time: the circadian clock and hypertension. J App/ Physiol 2009; 107: 1328-1338. 